Supporting Information for

\title{
Disordered Assembly of Donors and Acceptors on Layered Double Hydroxides for High-Efficient Chemiluminescence Resonance Energy Transfer
}

Lijuan Zhang, ${ }^{\dagger}$ Meina Shi, ${ }^{\dagger}$ Wenjuan Zhou,${ }^{\S}$ Weijiang Guan ${ }^{*}, \dagger$ and Chao Lu,,,,$+ \dagger$

${ }^{\dagger}$ State Key Laboratory of Chemical Resource Engineering, Beijing University of Chemical Technology, Beijing 100029, China

${ }^{\S}$ Department of Chemistry, Capital Normal University, Beijing, China

${ }^{\ddagger}$ Green Catalysis Center, and College of Chemistry, Zhengzhou University, Zhengzhou 450001, China

*E-mail: wjguan@mail.buct.edu.cn

*E-mail: luchao@mail.buct.edu.cn 


\section{Contents}

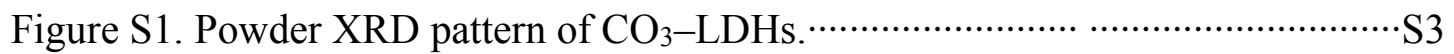

Figure S2. TEM image of $\mathrm{CO}_{3}-\mathrm{LDHs}$.

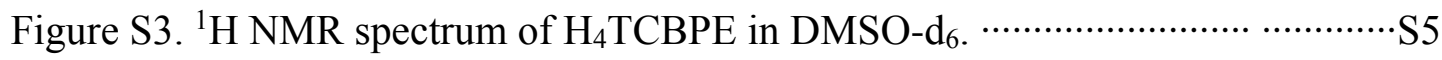

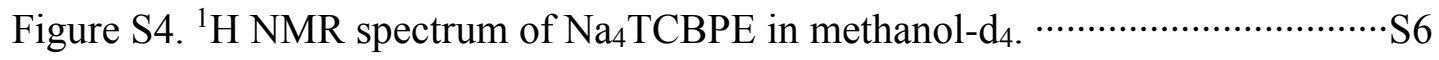

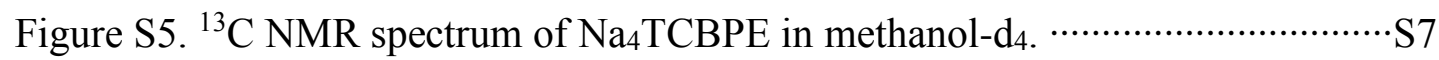

Figure S6. Negative ion mode ESI-MS spectrum of $\mathrm{Na}_{4} \mathrm{TCBPE} . \cdots \cdots \cdots \cdots \cdots \cdots \cdots \cdots \cdots \cdots \cdot \mathrm{S} 8$

Figure S7. (a) Fluorescence spectra of $\mathrm{Na}_{4} \mathrm{TCBPE}(1.0 \mathrm{mM})$ in $\mathrm{THF} / \mathrm{H}_{2} \mathrm{O}$ solvent mixtures with the THF fractions in the range from $0 \%$ to $98 \%$. (b) The plot of emission peak intensities of $\mathrm{Na} 4 \mathrm{TCBPE}(1.0 \mathrm{mM})$ in $\mathrm{THF} / \mathrm{H}_{2} \mathrm{O}$ solvent mixtures with increasing THF fractions. Each spectrum was measured three times, and the RSD values were less than $0.6 \%$. S9

Figure S8. Fluorescence spectra of LDH-supported $\mathrm{Na}_{4} \mathrm{TCBPE}$ at $\mathrm{Na}_{4} \mathrm{TCBPE}$ concentrations of $0.3,0.5,0.8,1.0$, and $1.3 \mathrm{mM}$. S 10

Figure S9. Fluorescence decay profiles of Na4TCBPE and LDH-supported $\mathrm{Na}_{4} \mathrm{TCBPE}$.

Figure $\mathrm{S} 10 . \mathrm{UV}-$ vis absorption spectrum of $\mathrm{Na}_{4} \mathrm{TCBPE}$.

Figure S11. Schematic diagram of the static injection CL analysis system. ……...S13

Figure S12. Excitation spectrum and chemical structure of eosin Y. S14

Figure S13. (a) Fluorescence emission spectra of different concentrations of eosin Y. (b) The plot of emission intensity versus the concentration of eosin Y. Each spectrum was measured three times, and the RSD values were less than $0.6 \%$. S15

Table S1. The Tolerable Concentrations of Some Interfering Species. S16 Table S2. Determination of $\mathrm{NaNO}_{2}$ in Real Samples. 


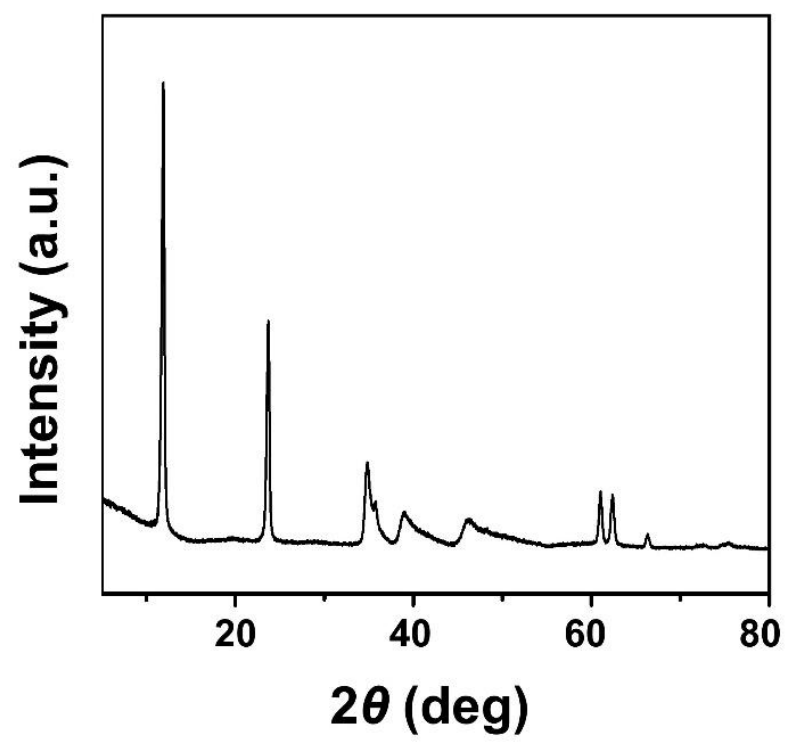

Figure S1. Powder XRD pattern of $\mathrm{CO}_{3}-\mathrm{LDHs}$. 


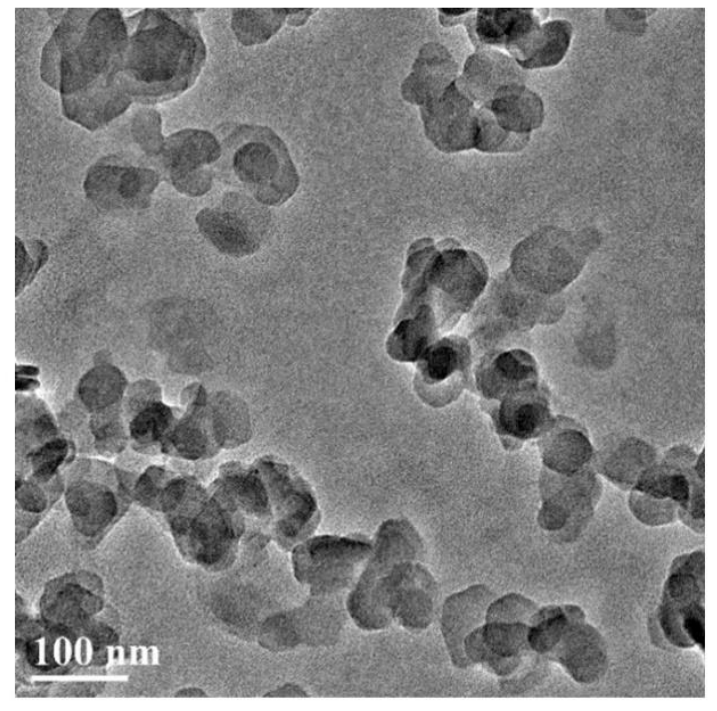

Figure S2. TEM image of $\mathrm{CO}_{3}-\mathrm{LDHs}$. 


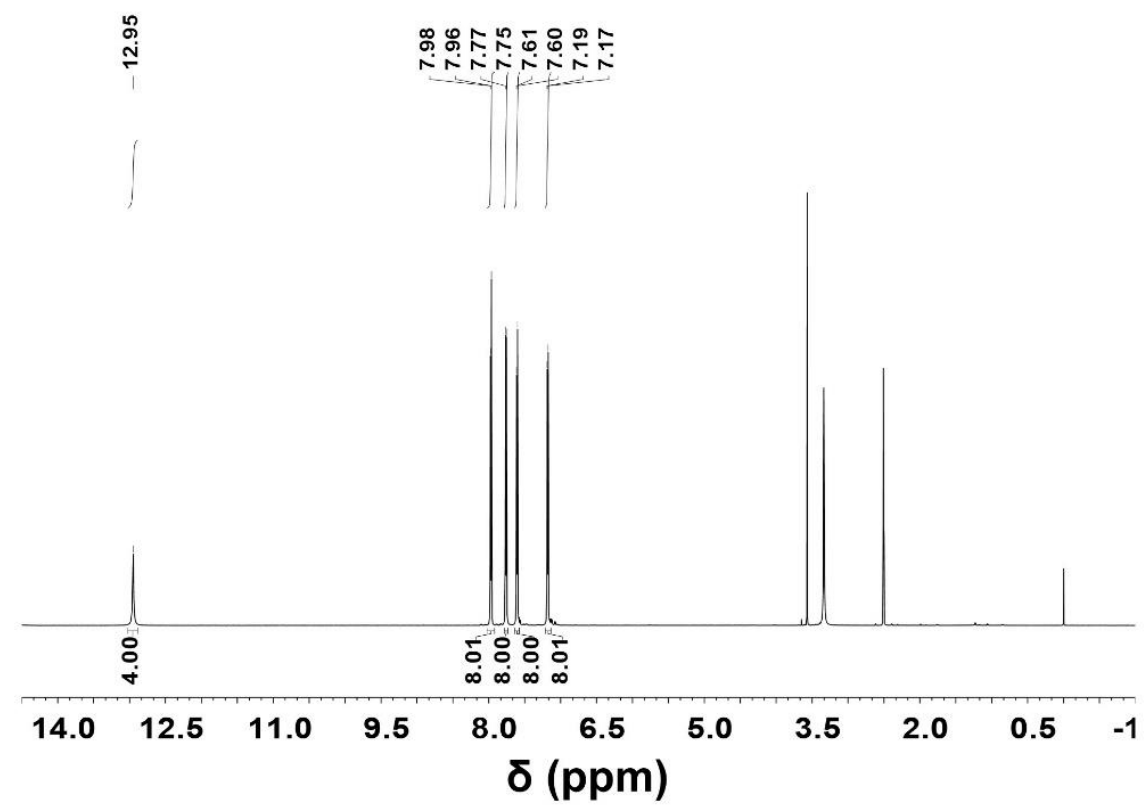

Figure S3. ${ }^{1} \mathrm{H}$ NMR spectrum of $\mathrm{H}_{4} \mathrm{TCBPE}$ in DMSO- $\mathrm{d}_{6}$. 


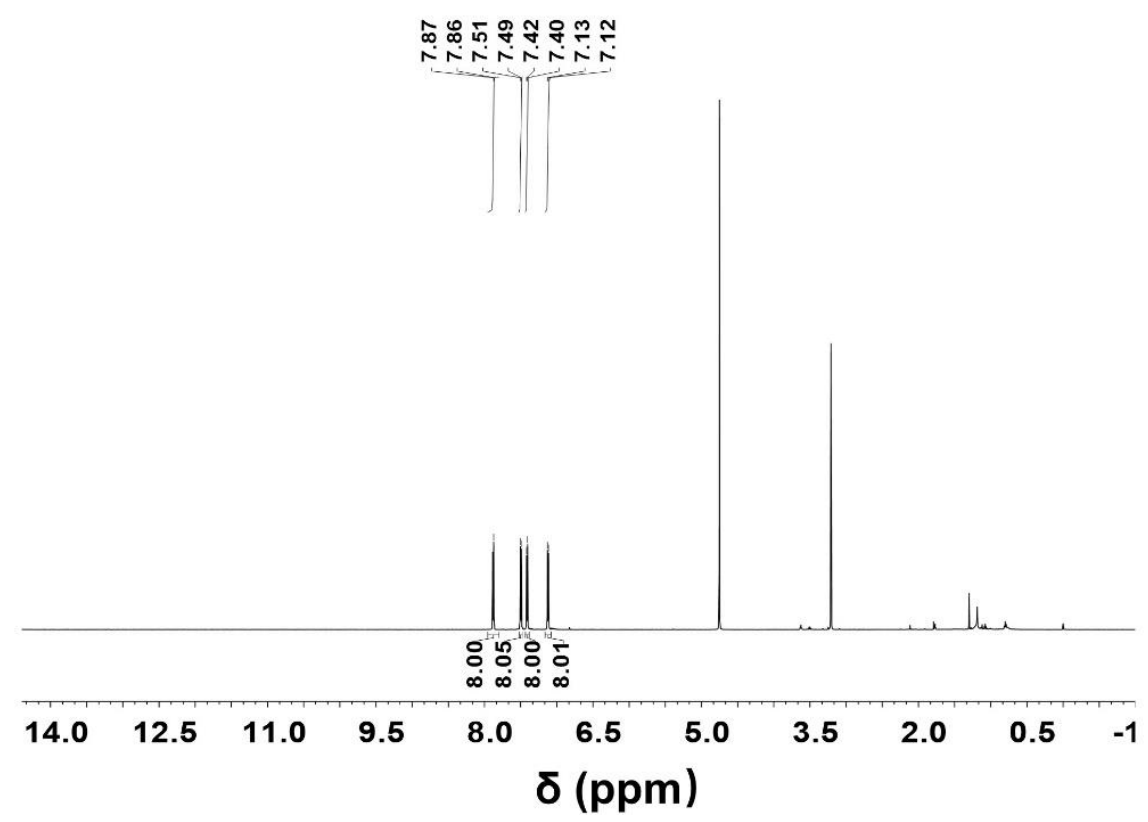

Figure S4. ${ }^{1} \mathrm{H}$ NMR spectrum of $\mathrm{Na}_{4} \mathrm{TCBPE}$ in methanol-d $\mathrm{d}_{4}$. 


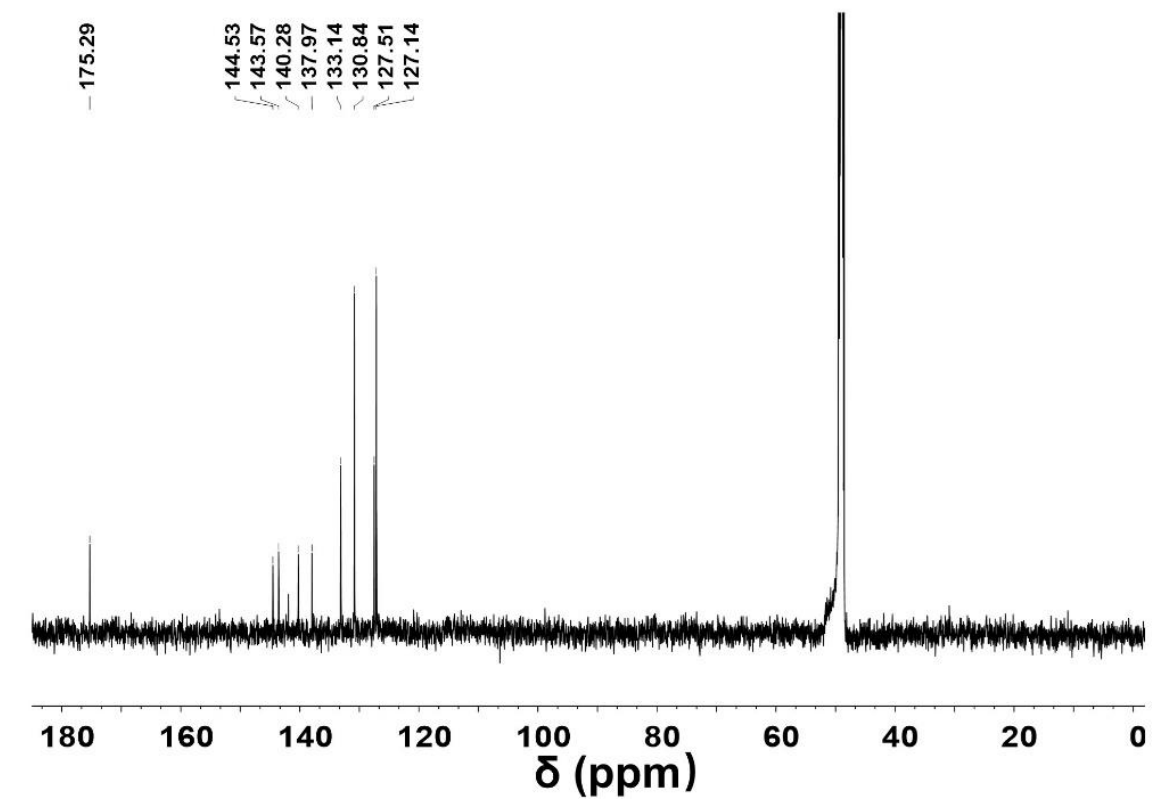

Figure S5. ${ }^{13} \mathrm{C}$ NMR spectrum of $\mathrm{Na}_{4} \mathrm{TCBPE}$ in methanol- $\mathrm{d}_{4}$. 


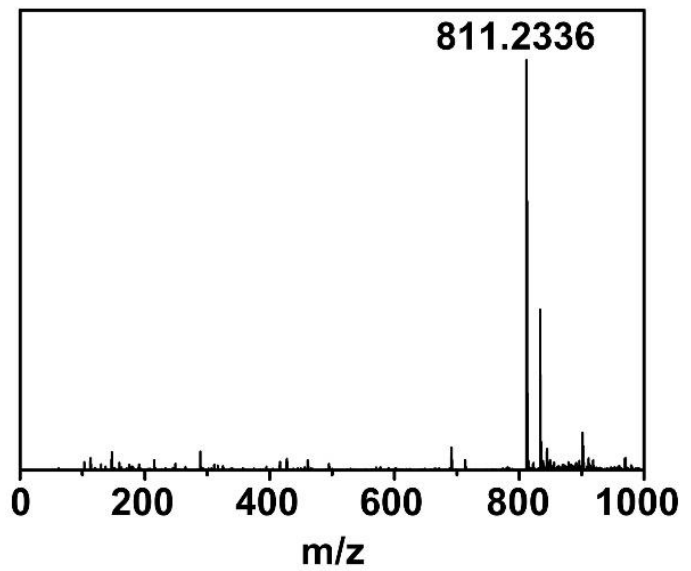

Figure S6. Negative ion mode ESI-MS spectrum of $\mathrm{Na}_{4}$ TCBPE. 

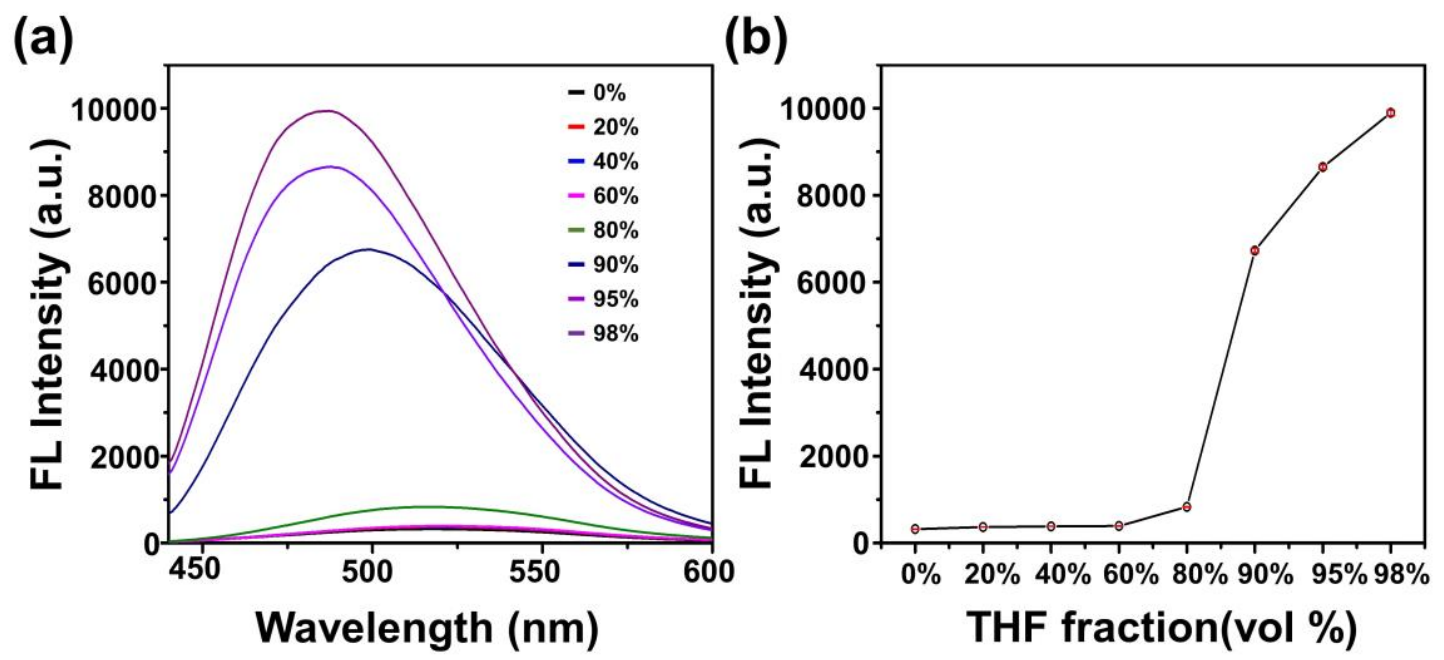

Figure S7. (a) Fluorescence spectra of $\mathrm{Na}_{4} \mathrm{TCBPE}(1.0 \mathrm{mM})$ in $\mathrm{THF} / \mathrm{H}_{2} \mathrm{O}$ solvent mixtures with the THF fractions in the range from $0 \%$ to $98 \%$. (b) The plot of emission peak intensities of $\mathrm{Na}_{4} \mathrm{TCBPE}(1.0 \mathrm{mM})$ in $\mathrm{THF} / \mathrm{H}_{2} \mathrm{O}$ solvent mixtures with increasing THF fractions. Each spectrum was measured three times, and the RSD values were less than $0.6 \%$. 


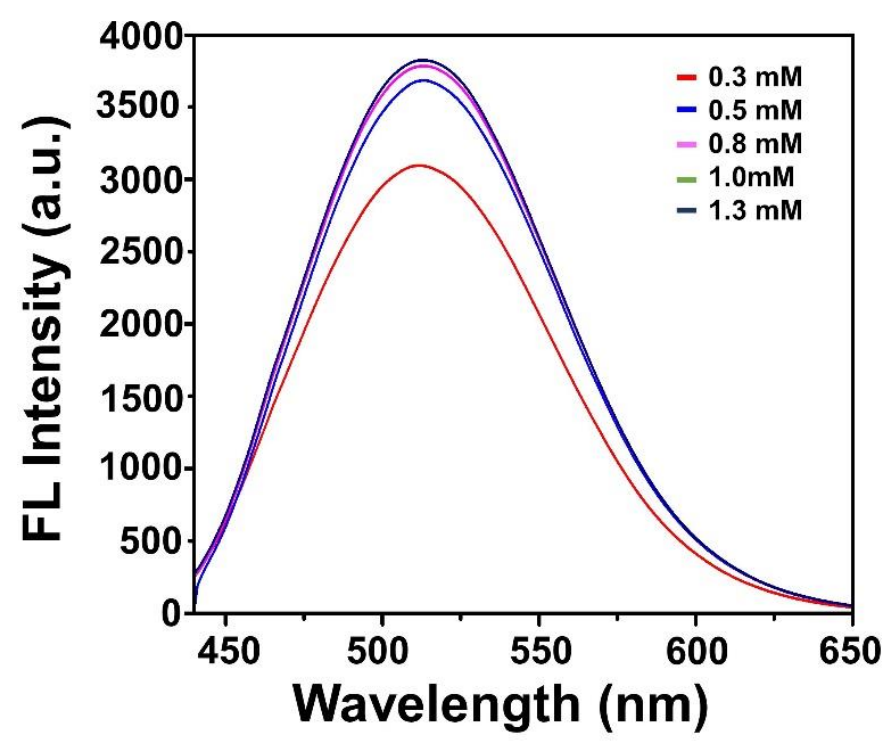

Figure S8. Fluorescence spectra of LDH-supported $\mathrm{Na}_{4} \mathrm{TCBPE}$ at $\mathrm{Na}_{4} \mathrm{TCBPE}$ concentrations of $0.3,0.5,0.8,1.0$, and $1.3 \mathrm{mM}$. 


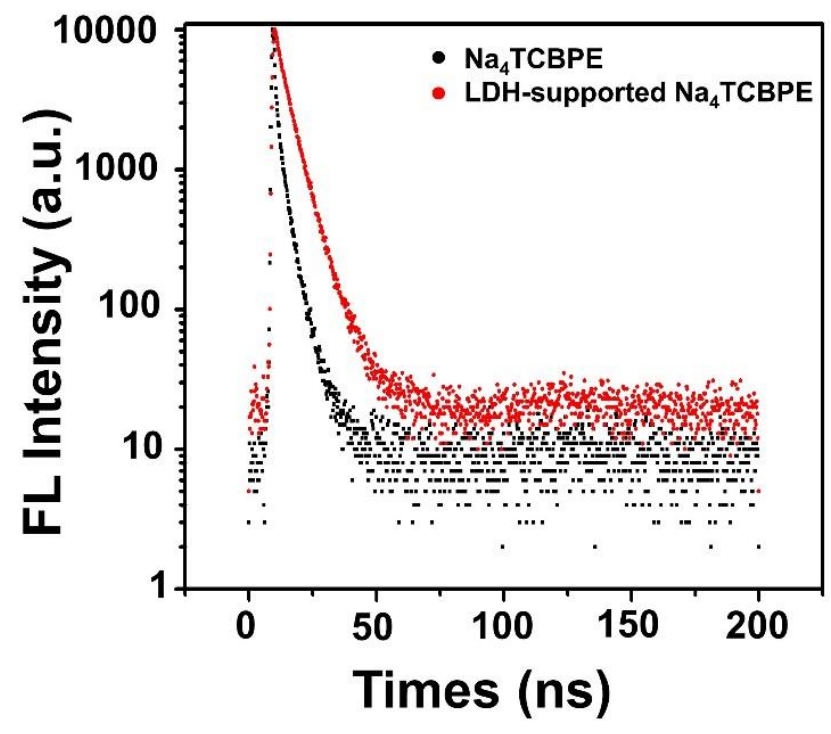

Figure S9. Fluorescence decay profiles of $\mathrm{Na}_{4}$ TCBPE and LDH-supported $\mathrm{Na}_{4}$ TCBPE. 


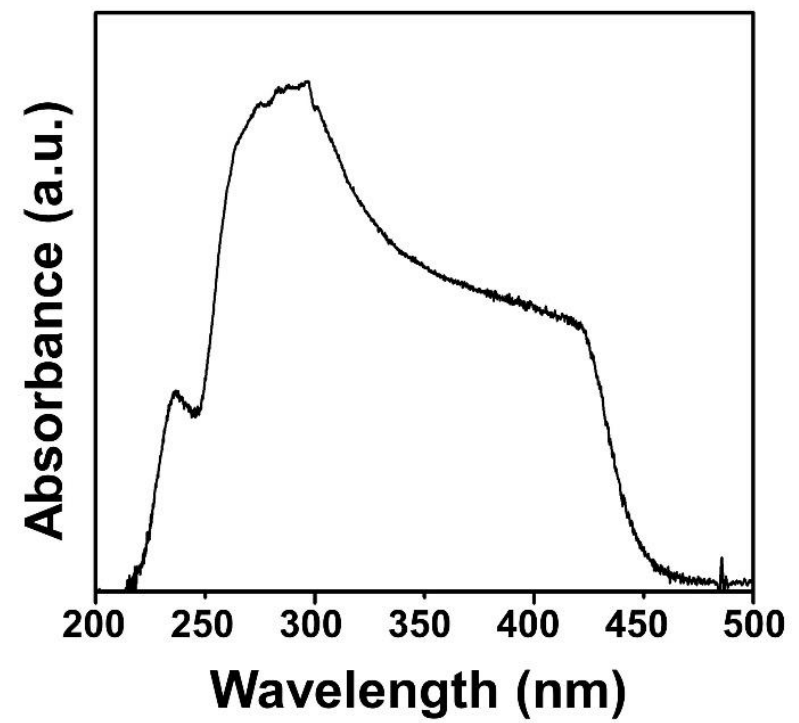

Figure S10. UV-vis absorption spectrum of $\mathrm{Na}_{4} \mathrm{TCBPE}$. 


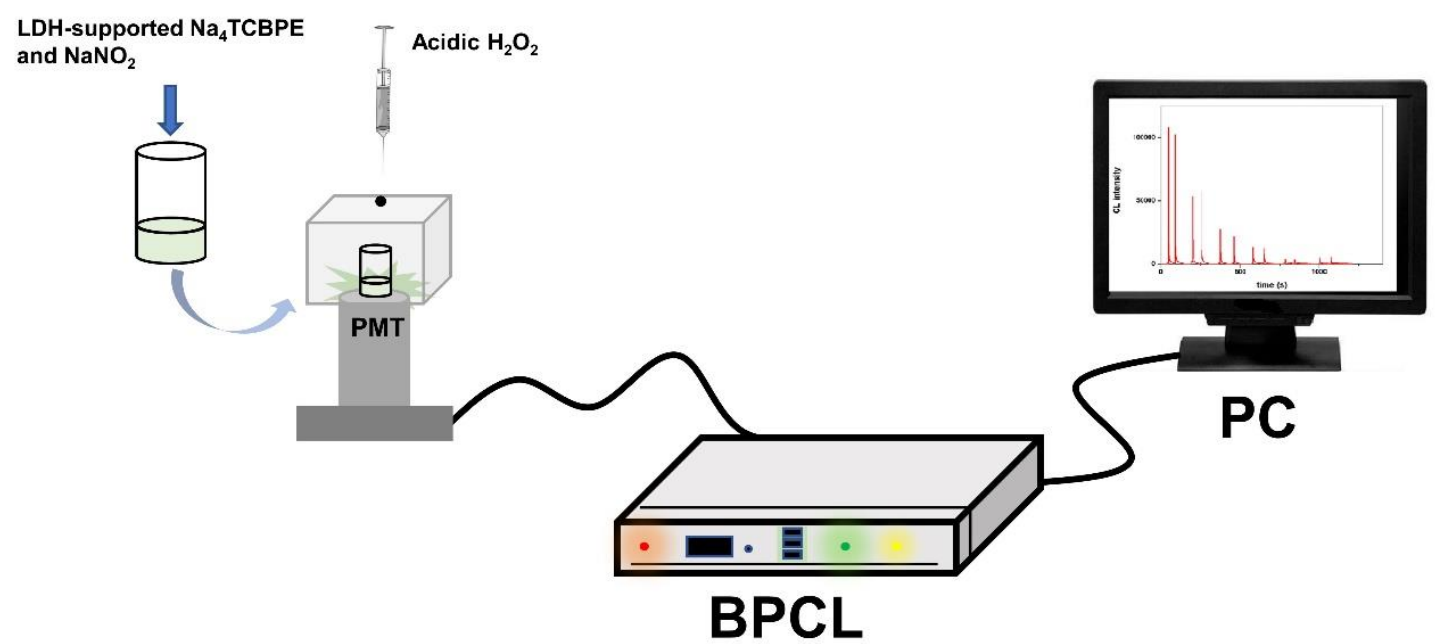

Figure S11. Schematic diagram of the static injection CL analysis system. 


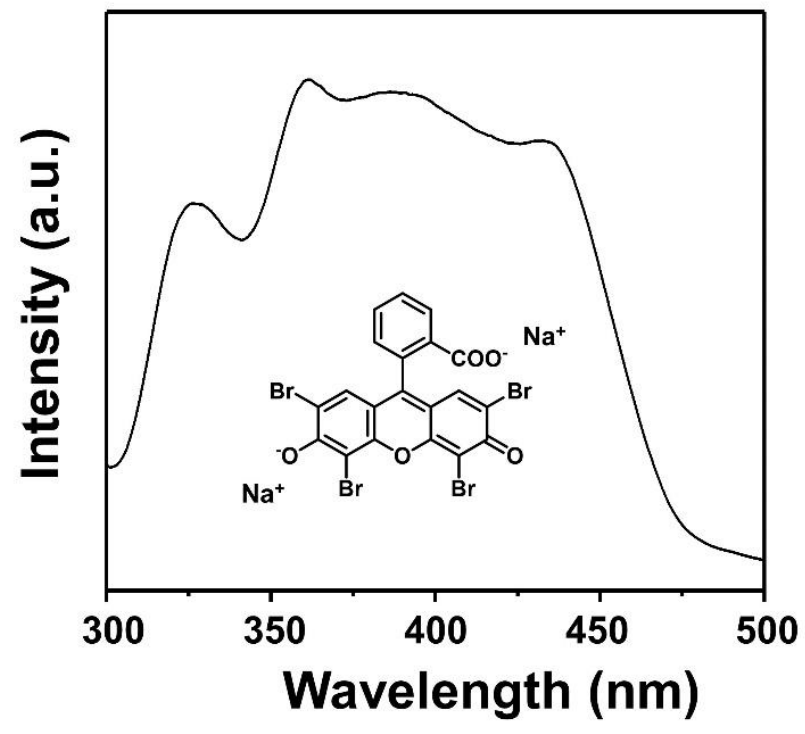

Figure S12. Excitation spectrum and chemical structure of eosin Y. 
(a)

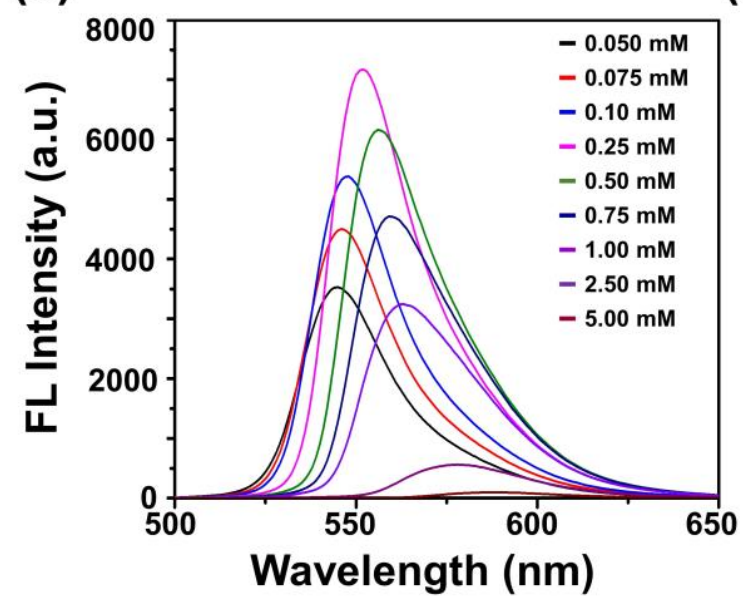

(b)

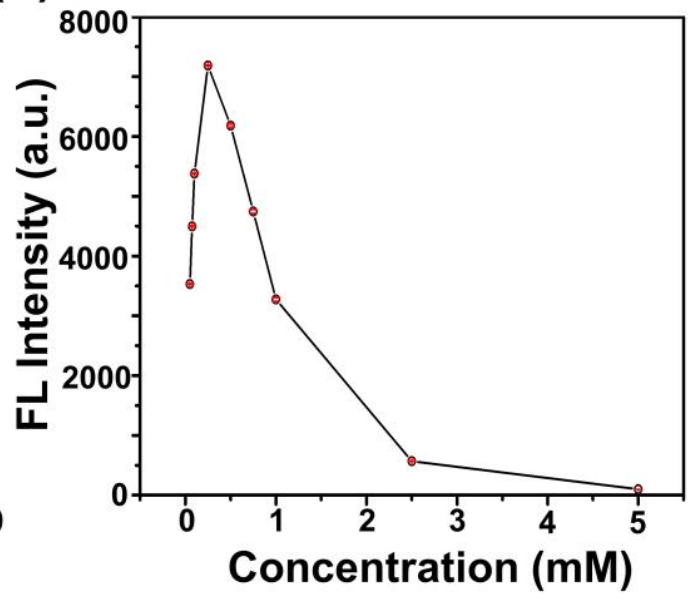

Figure S13. (a) Fluorescence emission spectra of different concentrations of eosin Y.

(b) The plot of emission intensity versus the concentration of eosin Y. Each spectrum was measured three times, and the RSD values were less than $0.6 \%$. 
Table S1. The Tolerable Concentrations of Some Interfering Species

\begin{tabular}{cc}
\hline Tolerance $(\mathbf{m M})$ & Coexistent substances \\
\hline 50 & $\mathrm{HPO}_{4}^{2-}, \mathrm{SO}_{3}^{2-}, \mathrm{Cl}^{-}$, glucose, sucrose \\
10 & $\mathrm{Ba}^{2+}, \mathrm{Cd}^{2+}, \mathrm{Co}^{2+}, \mathrm{Fe}^{3+}, \mathrm{Mg}^{2+}, \mathrm{SO}^{2+}, \mathrm{F}^{-}, \mathrm{H}_{2} \mathrm{PO}_{4}^{-}, \mathrm{Br}^{-}$ \\
5 & $\mathrm{Ac}^{-}, \mathrm{Ca}^{2+}, \mathrm{Ni}^{2+}, \mathrm{Cr}^{2+}, \mathrm{Cu}^{2+}, \mathrm{K}^{+}, \mathrm{I}^{-}$ \\
1 & $\mathrm{Al}^{3+}, \mathrm{PO}_{4}^{3-}, \mathrm{NO}_{3}{ }^{-}$ \\
\hline
\end{tabular}


Table S2. Determination of $\mathrm{NaNO}_{2}$ in Real Samples

\begin{tabular}{cccccc}
\hline Sample & $\begin{array}{c}\text { Proposed } \\
(\boldsymbol{\mu M})^{\mathbf{a}}\end{array}$ & $\begin{array}{c}\text { Standard } \\
(\boldsymbol{\mu M})^{\mathbf{a}}\end{array}$ & $\begin{array}{c}\text { Add } \\
(\boldsymbol{\mu M})\end{array}$ & $\begin{array}{c}\text { Found } \\
(\boldsymbol{\mu M})\end{array}$ & $\begin{array}{c}\text { Recovery } \\
(\mathbf{\%})\end{array}$ \\
\hline & & 4 & 4.24 & $106 \%$ \\
$\begin{array}{c}\text { Chicken } \\
\text { sausage }\end{array}$ & $2.57 \pm 0.01$ & $2.73 \pm 0.01$ & 6 & 6.01 & $100 \%$ \\
& & 10 & 10.28 & $103 \%$ \\
$\begin{array}{c}\text { Beef } \\
\text { sausage }\end{array}$ & $1.35 \pm 0.01$ & $1.14 \pm 0.01$ & 6 & 3.92 & $98 \%$ \\
& & & 10 & 10.18 & $102 \%$ \\
\hline
\end{tabular}

${ }^{\mathrm{a}}$ Mean \pm SD of three measurements. 